\title{
As relações sociais brasileiras em duas comédias de Martins Pena
}

\section{Brazilian social relations in two comedies of Martins Pena}

Manoel Candeias ${ }^{1}$ 


\section{Resumo}

Neste artigo, partimos de alguns importantes estudos sobre formação histórica e artística do Brasil para demonstrar de que maneira certas particularidades do contexto nacional estão expressas em duas peças de Martins Pena: O Judas em sábado de Aleluia e sua última comédia, que ficou sem título. Nesse percurso, observamo o modo pelo qual alguns procedimentos cômicos da tradição acabam por projetar formalmente tais especificidades locais.

Palavras-chave: Martins Pena; comédia brasileira; dramaturgia

\section{Abstract}

Based on some important studies on historical and artistic formation of Brazil we demonstrate in this article how certain particularities of the national context are expressed in two plays of Martins Pena: $O$ Judas em sábado de Aleluia (Judas at Alleluia Saturday) and his last comedy, which remained without any title. Following this path, we observe the way by which some traditional comic procedures end up designing formally such local specificities.

Keywords: Martins Pena; brazilian comedy; dramaturgy

ISSN: 1414.573

O século XIX brasileiro caracterizou-se por contradições sociais que se refletiram profundamente no dia a dia do país e, por conseguinte, em seu universo intelectual e produção artística. Ao mesmo tempo em que era um país latifundiário, dependente da mão de obra escrava, o Brasil produzia visando o comércio internacional e dessa forma, inseria-se na moderna economia mundial, dentro da qual a escravidão era um regime ultrapassado. Estados Unidos, França e Inglaterra, tidos como países avançados, seguiam novos rumos sob diretrizes liberais, como a igualdade perante a lei e a autonomia do sujeito. No Brasil, tais ideias eram valorizadas, mas não encontravam correspondência, porque a autonomia era negada não apenas ao escravo - 0 que seria coerente com a adaptação que a classe política brasileira criou para o discurso liberal (Bosi, 1988, passim) -, mas também a pessoas supostamente livres.

Para além dos escravos, restavam, no Brasil, basicamente duas classes sociais: os proprietários de terra e os homens brancos não proprietários. Sendo o país sustentado pelo trabalho forçado de negros, era reduzida a importância dos homens livres que não possuíssem os meios de produção, sobretudo porque os latifúndios brasileiros, em geral, consumiam apenas o que era produzido internamente, mantendo-se, assim, autossuficientes (Franco, 1987, p. 10-11). Dessa forma, os homens brancos ditos livres tinham pouca autonomia e, normalmente, dependiam de auxílios de algum proprietário para sobreviver. Assim, estabeleceram-se relações paternalistas, baseadas no favor. Em troca de um pedaço de terra para plantar ou, eventualmente, de uma indicação para cargos públicos, para citar dois exemplos recorrentes, esse homem intermediário trabalhava para angariar votos para seu padrinho ou prestava serviços e favores que ele exigisse em troca. Tal regime de relações espalhou-se pelo país:

Decerto existiam, na cidade como no campo, brasileiros brancos, livres e pobres. Mas a sua maior parte se constituía de "agregados", "moradores" "afilhados" "clientes" no sentido romano do termo - incorporados a cada uma das famílias de proprietários por laços parafamiliares, pela ideologia do favor e, frequentemente, pelo seu estatuto de "votantes" nas eleições (Alencastro, 1988, p. 50).

A relação baseada no favor, demonstra Roberto Schwarz em seu estudo acerca da presença dessas contradições no romance brasileiro², opõe-se completamente às bases do regime liberal, porque ao invés de garantir "[...] a autonomia da pessoa a universalidade da lei, a cultura desinteressada, a remuneração objetiva, a ética do trabalho etc.", promove "[...] a dependência da pessoa, a exceção à regra, a cultura interessada, remuneração e serviços pessoais" (Schwarz, 2007, p. 17).

O regime de favores tornou-se um mecanismo central das relações do Brasil escravista, mas não era o único reflexo da falta de colocação social dos homens brancos pobres - problema que atravessou a história do país por quatro séculos (Franco, 1997, p. 14). Martins Pena, cuja produção vai de 1833 a aproximadamente $1847^{3}$, traz, em suas comédias, boa parte dos sintomas dessa situação. $O$ favor não aparece muito diretamente, mas pode ser percebido em suas consequências, porque grande parcela

2 SCHWARZ, Roberto. Ao vencedor as batatas: forma literária e processo social nos inícios do romance brasilieiro. 5 ed. $3^{\text {a }}$ reimpressão.
São Paulo: Duas Cidades; Ed. 34, 2007, 240 p.
${ }^{3} A$ cronologia que utilizamos corresponde à da publicação preparada por Vilma Arêas: PENA, Martins. Martins Pena: Comédias. 3v. São 
dos enredos se concentra na vida de homens livres pobres, que sofrem justamente por não terem proteção de um grande e ainda precisarem enfrentar a concorrência com estrangeiros. A solução para essas personagens acaba sendo o recurso ao improviso e às pequenas falcatruas, porque vivem num país onde o trabalho, além de escasso, é menos valorizado que as contravenções. Veja-se, por exemplo, o seguinte diálogo de $O$ cigano (1845):

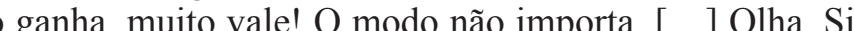
mão, o negócio lícito não dá nada! (Pena, 2007b, p. 224)

De modo semelhante, Maricota, de O Judas em sábado de Aleluia (1844), afirma: MARICOTA (só) - Tem razão; são milagres! Quando meu pai trabalhava pelo ofício e tinha um jornal certo, não podia viver; agora que não tem ofício nem jornal, vive sem necessidades. Bem diz o Capitão Ambrósio que os ofícios sem nome são os mais lucrativos (Idem, 2007a, p. 234-5)

E, em Os meirinhos (1845), há uma fala pontual de José, comumente destacada pelos estudos em torno de Martins Pena, quando se aborda essa questão:

JOSÉ - Regra geral: toda vez que uma maroteira render mais do que o cumprimento de um dever, haverá no mundo maior número de velhacos do que de homens de bem.

MANUEL - É verdade; tu ganhaste cinquenta mil-réis por uma maroteira, e eu, MAN UEL - E verdade, tu ganhaste cinquenta mil-réis por un

É recorrente, na obra de Pena, que as personagens encontrem-se sem alternativas e exponham verbalmente suas dificuldades, dando a impressão de que não têm muito o que fazer além de reclamar e inventar meios de sobrevivência, normalmente ilegais. Como complemento desse quadro, o dramaturgo explora também a interferência do privilégio, da influência e do poder pessoal sobre o cotidiano brasileiro. Algo que deturpava as leis, as relações, as separações entre público e privado, confundindo todas as fronteiras em favor de quem estava acima na hierarquia dos privilégios. Um exemplo em que esse critério se sobrepõe às leis é o relato de Clemência, de Os dois ou $O$ inglês maquinista (provavelmente de 1842), uma mulher de posses, que consegue um escravo contrabandeado, utilizando-se de uma rede de relações que envolve amizades e, sobretudo, pessoas que ocupam importantes cargos públicos:

CLEMÊNCIA - Empenhei-me com minha comadre, minha comadre empenhou-se com a mulher do desembargador, a mulher do desembargador pediu ao marido, es pediu a um deputado, o deputado ao ministro e fui servida (Idem, 2007a, p. 148).

Reforça essa ideia a fala de Ambrósio, de $O$ noviço (1845), que, casado no nordeste, passou a ter posses no Rio de Janeiro ao assumir um segundo matrimônio, com uma viúva rica. Depois de um breve receio de ser desmascarado, ele se acalma ao pensar numa regra que, de certa forma, percorre o país até hoje: "Se em algum tempo tiver de responder pelos meus atos, o ouro justificar-me-á e serei limpo de culpa. As leis criminais fizeram-se para os pobres!" (Idem, 2007b, p. 76, grifo nosso) Seu problema é que ostenta uma riqueza que estava condicionada ao golpe, ele não pertencia à camada privilegiada. Por isso, quando desmascarado, acaba preso.
O comportamento abusivo não se restringe, como se vê, às personagens que se encontram nas posições mais privilegiadas da sociedade, ele aparece nas ações de qualquer pessoa que veja a possibilidade de se proteger sob algum nome mais poderoso ou que esteja, um pouco que seja, acima de outra. Martins Pena flagra principalmente a faixa mais baixa, onde a desonestidade e as pequenas contravenções espelham essa moral coletiva, da qual, aparentemente, não se pode escapar. ${ }^{4}$ Sua primeira comédia, O juiz de paz da roça (provavelmente de 1833), tem na personagem que dá nome à peça uma figura absolutamente dominante, que, sem muito conhecimento sobre legislação, possui tal cargo e abusa tranquilamente da autoridade que tem nas mãos. Recebendo os requerentes na sala de sua casa, o juiz de paz de Martins Pena decide a posição da lei ao capricho de seu humor que pende claramente para a defesa daqueles que o presenteiam. Essa era uma situação muito comum no Brasil do século XIX, conforme descreve Maria Sylvia de Carvalho Franco, ao discorrer sobre as administrações locais da época: "Aí se vê o agente governamental imerso nas situações concretas em que desempenhava suas atribuições, funcionais, com sua conduta se orientando antes pelos fortes interesses e influências que envolviam sua vida de maneira imediata, que por longínquos e abstratos controles legais" (Franco, 1997, p.121)

Para isso contribuíam as más condições financeiras do governo, que acabava solicitando auxílios pessoais da população, para que suas instituições pudessem se erigir. O problema incluía a carência de prédios e instalações para o funcionamento dos serviços públicos, e, nesse caso, a saída "[...] foi pela utilização de propriedades particulares" (Ibidem, p. 130), algo muito comum durante todo o século XIX, conforme demonstram diversos documentos analisados por Maria Sylvia de Carvalho Franco. A partir dessa relação, a tendência era que tais pessoas tivessem um sentimento de propriedade sobre aquela instituição ou serviço público. Tendo esse sentimento, elas simplesmente controlariam tudo à sua maneira. Não parece ser outro o caso do juiz de paz da comédia, que faz de sua casa o tribunal da cidade. No Brasil, o uso do aparelho público para fins pessoais sempre foi recorrente, o que se insere naquela ideia de que a hierarquia do dinheiro e do poder era colocada acima de qualquer outro critério, relativizando até mesmo a objetividade das leis.

No universo mostrado por Martins Pena, a maior parte das pessoas parece agi de acordo com o interesse momentâneo, utilizando-se dos meios mais rápidos fáceis que estiverem ao seu alcance, independentemente de serem corretos ou não. Tudo isso sob uma aparência de normalidade, tornando padrão a adoção de comportamentos dúbios, dissimulados. O juiz de paz possui tal cargo público, mas o utiliza para fins pessoais; Gainer, de Os dois ou O inglês maquinista, elabora invenções mirabolantes, que servem apenas para tentar tirar dinheiro de brasileiros; Capitão Ambrósio, de $O$ Judas em sábado de Aleluia, usa de seu cargo para extorquir e castigar outras pessoas; Jorge, de Os irmãos das almas (1844), veste roupas religiosas pede doações para a igreja, mas separa uma parte da arrecadação para si; Marcelo, 
de O diletante (1844), Ambrósio, de O noviço (1845) e Manuel, de O caixeiro da taver na (1845), são comprometidos, mas buscam um segundo casamento com mulheres com mais posses que eles, visando o dinheiro; Manuel Igreja, sacristão de As desgraças de uma criança (1845), reza a morte de um homem tomado pela felicidade de saber que a viúva está livre para uma investida sua, e assim por diante.

Ao que parece, o Brasil não agia de modo muito diferente em suas relações internacionais, se considerarmos que o país criou leis proibindo o tráfico de negros ${ }^{5}$ mas continuou a recebê-los com grande intensidade. Porque suas leis e instituições eram controladas pelos principais interessados em manter a escravidão, que não hesitavam em adotar uma aparência para o mundo e praticar seu contrário internamente. O exemplo do jogo de dissimulações começava aí, mas se espalhava por diversas instâncias, como vimos pelas personagens de Pena. Por essa via, compreende-se aproximação que Antonio Candido (1993, p. 26) faz entre a obra de Martins Pena e Memórias de um sargento de milícias (1852). Em sua análise do romance de Manue Antônio de Almeida, Candido fala que há um estrato da obra, que lhe serve de princípio estrutural, no qual se estabelece a visão de uma dialética entre ordem e desordem, em que a oscilação das personagens entre um polo e outro é aceita como norma comum, criando "[...] uma espécie de terra-de-ninguém moral, onde a transgressão é apenas um matiz na gama que vem da norma e vai ao crime" (Ibidem, p. 44). Esse fundamento, ainda segundo o mesmo ensaio, seria o que dá àquele romance a cor local, o tom brasileiro.

Em sentido semelhante, duas peças de Martins Pena, O Judas em sábado de Aleluia (1844) e sua última comédia (sem título, provavelmente de 1847), possuem uma estrutura que, se não chega a reproduzir toda a complexidade do jogo de relações da sociedade brasileira, dá expressão a parte de suas peculiaridades.

O Judas em sábado de Aleluia mostra a trajetória do empregado público Faustino. Apaixonado pela namoradeira Maricota, ele tem de enfrentar inúmeros concorrentes, entre os quais um capitão da Guarda Nacional, que, sabendo amar a mesma moça que ele, utiliza-se de sua superioridade hierárquica para afastá-lo dela e castigá -lo6. A situação do capitão, que ainda cobra de outras pessoas para não as convocar para os serviços da guarda, é tão tranquila, que ele pode praticar seus abusos sem se preocupar muito em escondê-los. Apesar das evidências, Faustino não tem como provar que ele o convoca e manda prender por namorarem a mesma moça. Uma eventual queixa sua teria como opositor uma autoridade em posição de respeito público, que ainda poderia acusá-lo de ter fugido a um chamado oficial. A partir desse quadro de dominação, Pena cria uma saída que dialoga com a tradição cômica e se encaixa muito bem no contexto brasileiro da época. .

(1)

Faustino e Maricota conversam na sala da casa dela, quando ouvem a voz do Capitão Ambrósio, que chega da rua e pretende entrar. Ela foge, deixando o rapaz só, em vias de ser flagrado por seu opositor. Sem ter por onde escapar, Faustino veste a roupa do boneco do Judas, que está na sala desde a primeira cena, quando algumas crianças o preparavam, já que a história se passa em um sábado de Aleluia. Depois disso, o capitão entra e, naquela mesma sala, acontecem cenas com diversas personagens, todas observadas por Faustino. Assim, estando ele nessa posição de disfarce, as relações da peça se modificam, porque Faustino passa a estar presente sem estar, observa sem ser observado. Dentro dessa presença-ausência, ele passa a enxergar todos os outros sem disfarces, sem hipocrisia. Dessa forma, assiste à revelação de que seus opositores praticam uma série de atitudes desonestas, antiéticas e criminosas. E é isso que lhe servirá de arma para virar a mesa ao final.7 O sábado de Aleluia mostrado por Pena é a oportunidade única de Faustino agir como os outros para poder vencê-los. Ele assume uma falsa identidade, ou uma não-identidade - é o Judas sem o ser, assim como o capitão e os outros são pessoas de confiança do país sem, de fato, o serem -, e usa, ao final, tudo o que teve de informação privilegiada para chantagear seus opositores. No jogo de dubiedades e dissimulações daquele contexto, é pelo mesmo caminho, a falsa aparência e a posição privilegiada, que Faustino consegue vencer. Com isso, conquista para si uma liberdade, que não se sabe quanto durará, mas que permite a ele se impor diante do capitão e seus comparsas.

Dessa maneira, a peça se alinha à tradição farsesca, na qual "[...] a hierarquia social é contraposta a outra hierarquia, a da astúcia" (Schoell apud Minois, 2003, p. 203), invertendo, nesse caso, uma relação de dominação escorada muito mais no pequeno poder do que numa grande diferença de classe, já que o capitão também não era um proprietário de terras. Era, antes, alguém que se utilizava fortemente daquelas práticas recorrentes no Brasil, em que as fronteiras (entre público e privado, por exemplo) são diluídas em favor da dominação pessoal. A personagem presente-ausente, que age sob o disfarce, surge como uma solução para a reversão da hierarquia da influência que permeava o contexto nacional.

Algo na mesma linha pode ser reconhecido na última comédia (sem título) de Martins Pena, uma peça simples, objetiva e bastante dinâmica. Há uma importante cena no início, em que um homem chamado Luís entra na casa onde mora Júlia, tenta beijar sua mão e sai. Esse acontecimento fugaz ressoa sobre toda a comédia, interferindo nas decisões das personagens principais. $O$ tio da menina, dono da casa, entra logo que Luís se retirou e pergunta a ela quem saíra dali naquele instante. A sobrinha responde que ninguém e ele diz que pensou ter ouvido o som de um beijo. Ela afirma que é impressão dele. Carlos, marido de Júlia, está sumido há muitos anos e é perseguido pelo tio da moça, que trabalha como meirinho. Mas o rapaz não é reconhecido por ninguém e sempre arruma meios para enganar seus perseguidores. É tão competente nisso, que vai à casa do tio de Júlia, um dos meirinhos que o procura, 
apresentando-se como outra pessoa. Num desses momentos, o tio comenta com ele sobre a cena do beijo na mão de Júlia, sem saber que fala com o marido dela e alvo de sua busca; o marido, então, acha que a moça o traiu e fica mais tranquilo para flertar com outra moça; o tio, imaginando que o homem que beijara a mão da sobrinha deveria ser o marido que ele procura, acaba não acreditando no que Júlia fala, quando esta denuncia o marido fugitivo para o tio, mostrando-o à sua frente, dentro de sua própria casa. Negando a afirmação de Júlia, Carlos consegue convencer o tio de que não é o marido da sobrinha, justamente porque o tio desconfia de que ela o reencontrou de manhã, na cena do beijo, e está tentando protegê-lo contra o tio, que quer prendê-lo. Enfim, todo esse vai e vem trabalha em função do jogo de perseguição entre meirinhos e Carlos - o malandro mais completo de Martins Pena. ${ }^{8}$

Essa busca, que ridiculariza a capacidade policial dos meirinhos, cria uma ação centrada nos enganos e na urgência de perseguidores e fugitivo. Uma característica relevante nesse jogo é que, com a habilidade para burlar e confundir, Carlos consegue, em alguns momentos, estar presente sem estar. Chega-se ao ponto de ele sair junto com o meirinho à procura de si mesmo. Tudo porque consegue fazer com que esses profissionais da justiça brasileira acreditem que seu fugitivo tem características físicas diferentes das que realmente tem. Se Faustino, de $O$ Judas em sábado de Aleluia, precisa se disfarçar para conseguir espaço na sociedade, Carlos, da comédia sem título, já domina plenamente a moral nacional e em vez de se anular atrás de outra identidade (o boneco do Judas), lança sua identidade para outros portadores, ficando irreconhecível mesmo sem disfarce. Trata-se de outra espécie, portanto, de personagem presente-ausente, que surge como solução cômica para a superação da hierarquia social brasileira.

Vilma Arêas observa que a farsa e a pantomima, presentes na linguagem de Martins Pena, funcionam para retratar o jogo de aparências do contexto brasileiro, porque rejeitam um tipo consensual de mimesis e acabam por apontar "[...] como fingimento no mau sentido (mau "teatro") o desempenho dos papéis sociais e a falsidade de suas relações" (Arêas, 1987, p. 190). No caso de O Judas em sábado de Aleluia e da comédia sem título, a correspondência é ainda mais profunda, porque, sendo personagens que interferem nos rumos da peça sem estarem assumidamente presentes, Carlos Faustino reproduzem formalmente o regime de dissimulações que percorria a sociedade brasileira da época. As duas personagens ganham autonomia a partir do momento em que fazem da existência apenas parcialmente reconhecida uma opção. A incompletude da existência social, que normalmente lhes retira a capacidade de agir é, no recorte das peças, o que lhes serve de mecanismo para subverter o jogo de dominação que os cerca. E isso ocorre porque eles se utilizam das regras do contexto. $O$ disfarce e a dissimulação, que lhes permitem assumir o controle, não são diferentes daquilo que se encontrava nas instituições públicas e relações de favor, por exemplo.

Além disso, a personagem presente-ausente cria um movimento que poderíamos descrever como espiralar, porque Faustino e Carlos funcionam como um ${ }^{8}$ Antonio Candido (1993, p. 23) diferencia o malandro do pícaro de Memórias de um sargento de milícias, tem "[....] um amor pelo jogo-
pelos motivos de sua astúcia. Enquanto o segundo tem certo em-si", afirma, classificando-o mais como um malandro, um heró

pragmatismon nos fundamentos de suas açoes, normalmente visando opular, do que como um anti-heribi ponto fixo, com quem ou em torno do qual os outros se relacionam, até que se chegue ao desenlace. A história progride e há interação entre as personagens, porém, um dos lados (o da personagem presente-ausente, que é, nas duas peças, o protagonista) não sai do eixo, fazendo com que o movimento vá do início ao desfecho sempre circundando-o9. Assim, Martins Pena cria uma espécie de confinamento disfarçado, que obriga personagens que não dialogariam muito em outras circunstâncias a resolverem as diferenças no espaço de um ato, sem saltos no tempo ou mudanças de cenário.

Em outros termos, as peças trazem relações que funcionam como se fossem intersubjetivas, porém de modo cambaleante, porque apenas um dos lados sabe que interage com outro. De certa forma, era o que se via nas relações brasileiras, permedas pelo abuso de poder. No entanto, como são textos cômicos, a personagem que possui (uma espécie diferente de) autonomia e pode manipular os acontecimentos para turvar a perspectiva de sua contraparte é justamente aquela que, no contexto nacional, ocupava a outra posição, do sujeito que não tinha sua autonomia completamente estabelecida. Assim, essas duas peças de Martins Pena trazem, em forma e conteúdo, a inversão de hierarquia social da comédia. E, por meio desse recurso tradicional, acabam traduzindo parte das especificidades brasileiras de seu tempoalgumas delas, como o paternalismo ou a mistura entre público e privado, ainda hoje presentes no dia a dia do país.

\section{Referências}

ALENCASTRO, Luiz Felipe de. Proletários e escravos: imigrantes portugueses e cativos africanos no Rio de Janeiro, 1850-1872. In: Revista Novos estudos, Ed. 21, Julho de 1988 , p. 30-56

ARÊAS, Vilma. Na tapera de Santa Cruz: uma leitura de Martins Pena. São Paulo: Martins Fontes, 1987.

BOSI, Alfredo. A escravidão entre dois liberalismos. In: Estudos avançados [online] 1988 , vol. 2, n. 3, p. 4-39.

RASIL. Presidência da República. Casa Civil. Subchefia para assuntos jurídicos. Disponível em: http://www.planalto.gov.br/ccivil_03/Leis/LIM/LIM581.htm. Acesso em 10 mar 2014.

CANDIDO, Antonio. Dialética da malandragem. In: CANDIDO, Antonio. O discurso e a cidade. São Paulo: Duas Cidades, 1993

Vilma Arêas (1987, p. 188) reconhece nessas duas comédias um movimento que ela descreve como circular, mas que diz respeito dinâmica de fuga e perseguiçáa que atravessa a cena, e compara Labiche que seria encenado alguns anos depois, em 1851 . 0 que apontamos não anula sua observação, mas diz respeito ao modo

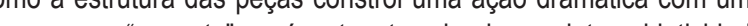
prsonagem "ausente", porém atuante, criando uma intersubjetividad a enter deixa de avanç̧â. 
FRANCO, Maria Sylvia de Carvalho. Homens livres na ordem escravocrata. São Paulo: UNESP, 1997.

MAGALHÃES JÚNIOR, Raimundo. Martins Pena e sua época. São Paulo: Lisa, 1972.

MINOIS, Georges. História do riso e do escárnio. São Paulo: UNESP, 2003.

PENA, Martins. Martins Pena: Comédias (1833-1844). São Paulo: WMF Martins Fontes, 2007.

Martins Pena: Comédias (1844-1845). São Paulo: WMF Martins

Fontes, 2007.

Martins Pena: Comédias (1845-1847). São Paulo: WMF Mar-

tins Fontes, 2007.

SCHWARZ, Roberto. Ao vencedor as batatas: forma literária e processo social nos inícios do romance brasileiro. São Paulo: Duas Cidades; Ed. 34, 2007.

Recebido em 22/05/2014 Aprovado em 23/06/2014 